\title{
$9-5-2014$
}

\section{The Physics of Music Course as an Introduction to Science}

\author{
Gordon Ramsey \\ Loyola University Chicago, gramsey@luc.edu
}

Follow this and additional works at: https://ecommons.luc.edu/physics_facpubs

Part of the Physics Commons

\section{Recommended Citation}

Ramsey, G. (2014). The physics of music course as an introduction to science. Proceedings of Meetings on Acoustics, Vol. 18 (2014).

This Article is brought to you for free and open access by the Faculty Publications and Other Works by Department at Loyola eCommons. It has been accepted for inclusion in Physics: Faculty Publications and Other Works by an authorized administrator of Loyola eCommons. For more information, please contact ecommons@luc.edu. cc) (i) $\Theta \Theta$

This work is licensed under a Creative Commons Attribution-Noncommercial-No Derivative Works 3.0 License. (C) 2014 Acoustical Society of America. 


\title{
Proceedings of Meetings on Acoustics
}

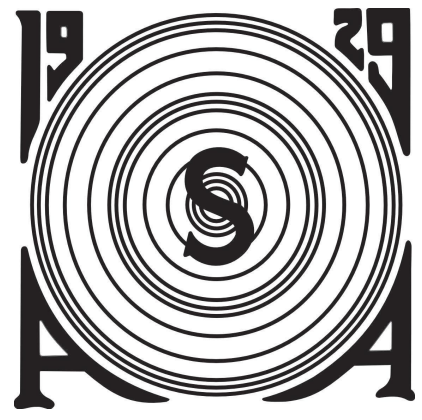

\section{4th Meeting of the Acoustical Society of America Kansas City, Missouri 22 - 26 October 2012}

\section{Session 2pMU: Musical Acoustics}

\section{2pMU2. The Physics of Music course as an introduction to Science}

\author{
Gordon Ramsey*
}

*Corresponding author's address: Physics, Loyola University Chicago, Chicago, IL 60660, gprspinphys@yahoo.com

Our Physics of Music course is an integration of physics and music. We start with the mathematical structure of music, including scales, harmonies and chords. We discuss musical styles and how they differ. After an introduction of physics concepts, including waves, resonances, forces, energy and fluid flow, the physical structure of instruments in the various groups are studied. Connection is made of the instruments and how they reproduce the mathematical nature of music. Finally, venue acoustics are investigated. The course integrates different styles of learning by integrating different learning modes. The classes include lecture/demonstration, discussion, in-class laboratories and a final individual project encompassing many course elements. The constant connection between the physics and the music, along with varied learning techniques, including hands-on experience, provides a motivating approach for non-science majors to experience science in a familiar context.

Published by the Acoustical Society of America through the American Institute of Physics 


\section{INTRODUCTION}

The Physics of Music course at Loyola University Chicago is multidisciplinary, in that it consists mainly of musical structure and the physical aspects of instruments and room acoustics. However, elements of physiology, mainly of the ear and brain, sociology (in its influence on musical tastes of populations) and psychology of the listener's interpretation of musical pieces being heard, are interjected in appropriate places in the course. The goal is to integrate these concepts so students leave the course with a broad perspective of the overall construction and interpretation of music. The prerequisite is college algebra and preferably, an exposure to trigonometry.

The course consists of both writing and quantitative material. At the end of the course, certain learning outcomes and skill levels are expected to be achieved. The learning outcomes expected in the course include:

- Knowledge of music fundamentals

- Gain an appreciation of music as an art form and its performance as an artistic and technical combination of human elements

- To interpret waveforms and how they relate to perceived sounds

- Ability to recognize the instrument groups and to understand how they function

- Understand how the ideas and techniques of physics are used to analyze sound, operation of instruments and the propagation of musical sound

- Knowledge of inquiry and laboratory techniques in the pursuit of knowledge of the technical aspects of music and its production.

The following literacy skills should also be acquired by the end of the course:

- To be able to recognize the instrument groups and to understand how they function

- To recognize the key elements of music and properties of the musical instruments

- To be able to mathematically analyze waves

- To know how to model sounds of the various musical groups

- To use mathematical and experimental skills to analyze musical instruments

- To comprehend physical concepts and apply them to the analysis of sound and instruments

- To distinguish the artistic and scientific thought processes in their application to music

- To understand oral, written and musical expression as human communication.

Those provide the goals for designing the course. The course elements are diverse and include a cross section of qualitative and quantitative exposure to the topics. The following section describes these elements.

\section{COURSE DESCRIPTION}

The course integrates physics and music. We start with the mathematical structure of music, including scales, harmonies and chords. We discuss the evolution of musical styles in light of melody, harmony and rhythm, and how the styles differ. After an introduction of physics concepts, including waves, resonances, forces, energy and fluid flow, the physical structure of instruments in the various groups are studied. Connection of the physical concepts. is made to the instruments and how they reproduce the mathematical nature of music. Finally, venue acoustics are investigated. We found that the appropriate text at this level is by Donald Hall.[1] Excerpts from Rossing and Olson are also used.[2, 3]

\section{Syllabus}

The course consists of three major units:

1. Language and structure of music (about 20\%)

2. Physical concepts used the study of musical acoustics (about 30\%)

3. Physics of musical instrument groups and venues, electronic music and miscellaneous topics. (about 50\%) 
The mathematical structure of music starts with single notes and includes scales, chords and the elements of melody, harmony and rhythm. The musical instrument groups are introduced in terms of their structure, sounds and musical ranges. The unit concludes with a presentation of the history and evolution of musical styles, from Gregorian Chant to the diverse musical styles of today. We have a brief discussion of instrumentation used in the different musical styles. This is revisited later in the course when the students have studied the design and physical properties of each instrument group, with additional insight gained from understanding the physics behind them. This unit covers about three weeks of the course.

The physics unit includes the following topics, discussed in the context of musical acoustics:

- introduction of physics as a science: modeling and experimentation

- forces and pressure, especially applied to fluids and solid membranes

- energy, power and intensity

- transverse and longitudinal waves and their properties

- superposition and resonances

- description of simple harmonic motion and cyclic phenomena

- application of physical concepts to musical instruments.

Since most of the students in the course are not science majors, it is important to describe physics as a science in terms of modeling phenomena and testing the models with experimentation. We talk about measurement and errors on a simple level. Estimation of errors, absolute and relative errors are presented with algebraic techniques used to calculate them. These are reinforced by the in-class labs that are done throughout the course. The physical concepts that are applicable to musical acoustics are covered with algebra and a bit of trigonometry. Only sines and cosines are introduced to describe periodic phenomena. To put the physical concepts in perspective, we discuss a few non-musical applications of these concepts such as simple harmonic oscillators (springs and pendulums). The physics unit takes about four weeks to cover, including three labs.

The remainder of the course covers the final unit, where we combine the music and physics concepts to describe the design and properties of the main musical instrument groups: strings, woodwinds, brass, percussion, the voice and electronic music. The course concludes with room acoustics and perception of music. The acoustics allows the introduction of the physical properties of sound waves, including reflection, diffraction, absorption and the Doppler effect. The interpretation includes discussion of the ear, the role of the brain, psycho-acoustic factors and effects of social background of the listener.

\section{Class constituents}

A survey is taken during the first week of class to determine the musical, mathematical and scientific background of the students enrolled. Topics of the survey include:

- musical instruments played (including voice)

- knowledge of music theory

- highest level of mathematics taken

- previous physics courses in high school or college, and

- favorite musical styles.

The results are tabulated to determine the level of each topic to present or emphasize. Anyone lacking the prerequisite skills is asked to see me for guidance. This is entirely voluntary, but encouraged, since the surveys are anonymous. Normally, there is a wide spectrum of students, from business and education majors to physics majors. This presents a challenge to teach, but the level of the course is meant for a general audience. On average, about $75 \%$ of students have a musical background and about $60 \%$ read music and have a knowledge of music theory, although neither is required.

A typical population of the class includes about $67 \%$ non-science majors and $33 \%$ science majors, spread across many majors. The largest single group are humanities majors, a small fraction of which includes music majors. All have had algebra (a prerequisite) and most have had at least an exposure to sinusoidal functions. Nearly two-thirds of the students have had a course in calculus. However, the competence in algebra is very mixed. Most have a decent working knowledge, but a few are very uncomfortable with algebra. There are tutorials available for those students. 
The favorite musical styles vary considerably. About two-thirds like rock and pop, while nearly $60 \%$ on average like jazz. Classical music is listed by about half the students. These are the most popular. There are a minority of respondents who list "all kinds" as their favorite. During the music portion of the course, music history and development of styles is discussed. Since the students typically like many styles, they often comment on each of the genres presented.

\section{COURSE ELEMENTS}

The course integrates different styles of learning by integrating different learning modes. The classes include lecture/demonstration, discussion, in-class laboratories and a final individual project encompassing many course elements. The constant connection between the physics and the music, along with varied learning techniques, including hands-on experience, provides a motivating approach for non-science majors to experience science in a familiar context.

\section{Homework and Exams}

Homework is assigned approximately weekly and graded. The purpose of the homework is to give students practice at (i) reflecting on the conceptual topics in the course and (ii) doing quantitative calculations that give students a perspective on the scales of physical variables that play a role in music. Thus, the homework is a combination of qualitative and quantitative problems. Algebra is a prerequisite and the only trig that is used is the idea of a sinusoidal wave. This concept is introduced through various demonstrations and Web videos illustrating sound as a vibrational wave. Homework solutions and discussion are done once the class has submitted the assignment. There are three hourly exams that reflect the homework coverage and are a combination of conceptual and mathematical problems. Although there is a comprehensive final exam, it only counts the same as an hourly exam.

\section{In-class Labs}

The labs provide hands-on experience in testing measurement and analysis of physical data. Since most of the students are not science majors, this may be the only exposure to experimentation that they receive in their college career. The four labs performed are:

1. Sound as a wave - at the beginning of the physics section

2. Simple harmonic motion lab - middle of the physics section

3. Standing waves - at the end of the physics section

4. Instrument lab with longitudinal and transverse waves - middle of the instrument section

The first lab introduces the relation between frequency and fundamental note heard. Complex waveforms and their structure are analyzed with simple chords. The second analyzes simple harmonic motion with mechanical waves, including the pendulum and spring motion. Differences between mechanical and auditory waves are investigated. The third lab studies transverse and longitudinal waves in instruments, distinguishing similarities and differences in the two. The final lab investigates the timbre of various musical instrument groups via spectral analysis.

During the lab, students are called up alphabetically to take measurements for each part of the lab. The experiments are designed so that sufficient data can be taken during one class period of fifty minutes. Since most of the students are not science majors, they are instructed on the essential elements of a scientific lab report. Once the data are taken for a given lab, the students have one week to hand in their report. Extensive comments are made when grading so they can fine tune their technical writing skills for each successive lab. By the end of the semester, most students have at least a rudimentary idea of what should constitute a reasonable lab report. The following is an outline of a typical report.

Introduction This should include the objective of the lab and an overview of the purpose. This includes a brief description of how the lab supports the course topics.

Procedure This includes a brief description of the equipment and a procedure in the students' own words. 
Data The data is filled in on a spreadsheet and most of the calculations, especially those involving expected errors, are done automatically by the spreadsheet calculator. Although we discuss error estimation and calculations in class prior to the lab, the students are not expected to program the spreadsheet. They must show a sample calculation of each type by hand, however.

\section{Discussion of results}

Brief error discussion This is mostly qualitative, with reference to the quantitative results in the spreadsheet. The discussion should include accuracy and precision of results and the overall conclusion and to the significance of the results.

Conclusion The final section summarizes the results, significance and effectiveness of the experiment. Final statements on how the understanding of the course topics are enhanced by the lab.

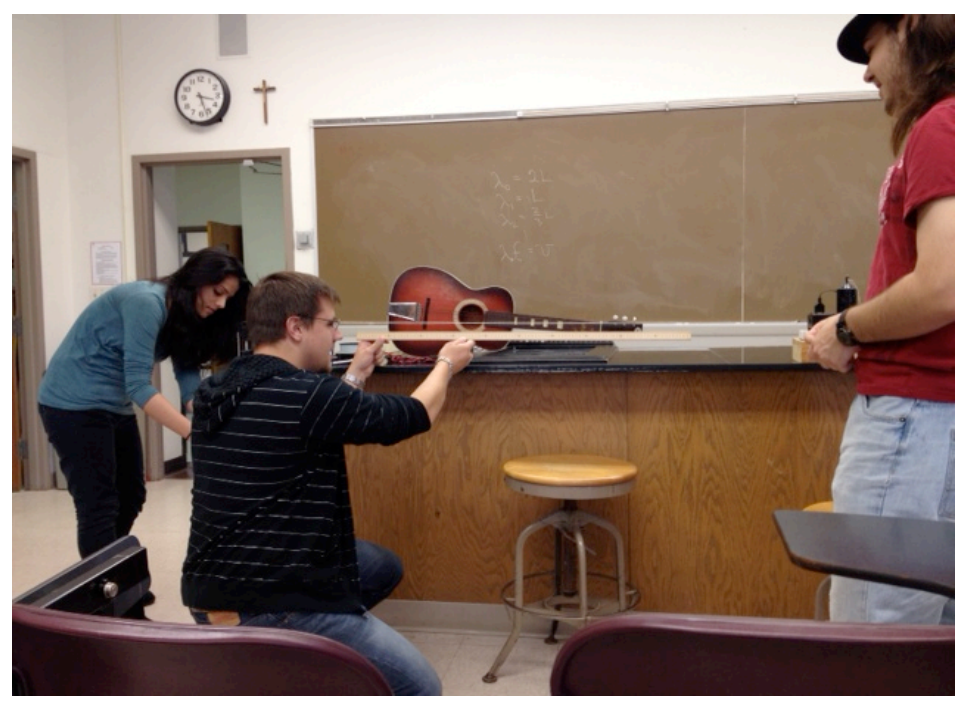

FIGURE 1. Typical in-class experiment in the Physics of Music course.

\section{Course Project}

The course project elements include: initial proposal, an intermediate report (option), a final report and demonstration of any built instrument. All projects must include a musical element, a physics element and a link between the two. Previously performed projects include: building an instrument, description of an instrumental group, measurement of room acoustics for a performance room on campus, analyzing a musical production attended in the city or a previously approved related topic. We discuss an overview of the project elements approximately six weeks prior to the semester's end. This gives the students a chance to sample many aspects of the topics and instrument properties. 
The project proposal is due four weeks prior to semester end. Suggestions for proceeding are given and an appropriate direction is suggested for a successful project. A midterm project status report is due two weeks later and the final project paper is handed in on the day of the final exam. Those students building an instrument must demonstrate its operation during the last week of class. The extent to which the instrument works is part of the grade.

\section{CONCLUSION}

The Physics of Music course at Loyola has been successful and well received due to its multidisciplinary content. It has attracted students of all majors. The content and expectations of students provide a comprehensive one-semester interdisciplinary course on the connection of physics to music.

\section{REFERENCES}

1. D. E. Hall, Musical Acoustics, 3rd Ed., Brooks/Cole Publishing, Pacific Grove, CA, 2002.

2. T. D. Rossing, F. R. Moore and P. A. Wheeler, The Science of Sound, 3rd Ed., Addison-Wesley, San Francisco, CA, 2002.

3. H. F. Olson, Music, Physics and Engineering, 2nd Ed., Dover Publications, Inc., New York, NY, 1967. 